\title{
Modelling the thermal sterilisation of foods inside packs with two divisions
}

\author{
Isabel M.L.B. Ávila, Maria da Conceição Manso, Cristina L.M. Silva* \\ Escola Superior de Biotecnologia, Universidade Católica Portuguesa, Rua Dr. António Bernardino de Almeida, \\ 4200 Porto, Portugal
}

\begin{abstract}
A mathematical model was developed to describe the heat transfer during the sterilisation of conduction heating foods inside three dimensional two division rectangular packs. The model uses a standard explicit finite differences method with non-capacitance surface nodes and simulates different pack sizes, food properties and surface heat transfer resistances at the package lid and walls. Taking into account the cooling phase, the sterility value was calculated as a function of position in order to identify the location of the least lethality point. The most important variables affecting the position of this point are the product heating rate and the surface heat transfer coefficients. For low heating rate values this critical point moves towards the surface. When different food products are sterilised in simultaneously the quality degradation of foods in this type of package is also a point of discussion.
\end{abstract}

\section{Introduction}

Nowdays new packages for sterilised conduction heating foods have been developed to improve the market image of products. An example is the plastic two division pack with metal lids. These types of containers are also used for ready to eat microwave reheating meals [1].

Several authors have published mathematical models to describe the heat transfer into one division rectangular packages [1-5]. These models are an essential tool to design adequate sterilisation processing conditions assuring the safety of the final product. Due to the fragility of semi-rigid plastic containers, pressurised water or pressurised steam/air mixtures are usually used; however, these types of sterilisation heating mediums lead to the existence of heat transfer resistance at the surface of the container. Furthermore, the plastic material and also the headspace at the top of the product lead to additional resistances to heat transfer. Tucker and Holdsworth [4,5] developed a computer program to simulate the sterilisation of conduction heating foods, under experimental conditions as described above, and used the results to determine optimum conditions minimising the final overall cook value. 
The packages with two rectangular divisions are very practical from the consumer point of view. However, the existence of different food products, processed under the same sterilisation time-temperature heating conditions, represent a real problem regarding the final safety and quality. To mathematically model the thermal sterilisation of meals in this type of pack, it is necessary to consider two rectangular containers at the same time and define adequate criteria to assure the safety in both divisions. Both rectangular containers have also to be considered if optimum conditions for maximising the final quality of the overall meal are to be determined. There is currently an absence of any literature dealing with this problem.

To adequately sterilise conduction heating pre-packaged foods, a minimum target sterility value must be assured in all points [6]. According to Tucker and Clark [3] the contribution of the cooling phase to the final sterility of products in rectangular containers is significant. Generally, the geometric center is considered as the least lethality point; however, this approach may not be correct when including the cooling phase in the lethality calculation [7]. Depending on different processing variables, the least-lethality point position does not always lie at the geometric centre. The studies developed on this matter were only applied to cylindrical containers considering processing conditions with no surface resistance to heat transfer [7] and processing conditions with finite heat transfer coefficient at the product surface [8]. There is not any research study on the location of the least lethality point for rectangular geometries.

Therefore, the objectives of this research study were: (1) the development of a model to describe the thermal sterilisation of different food products in packages with two rectangular divisions and (2) the definition of the most adequate sterilisation criteria for rectangular containers.

\section{Methods}

A mathematical model, using a single step standard explicit finite differences method with non-capacitance surface nodes was developed to describe the heat transfer into packs with two rectangular divisions (Fig. 1) filled with conduction heating products [9]. A gridwork with nine nodes in the directions $x, y$ and $z$ (as shown in Fig. 2) was set up.

This numerical method was introduced in a Pascal computer program to simulate the thermal sterilisation for this type of packages. The model assumed: (1) constant holding temperature without come-up-time, followed by step cooling to $20^{\circ} \mathrm{C}$, (2) constant thermal properties for the food products in each division, (3) first order inactivation kinetics both for the target microorganism (Clostridium botulinum) and quality

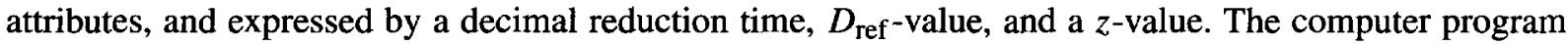

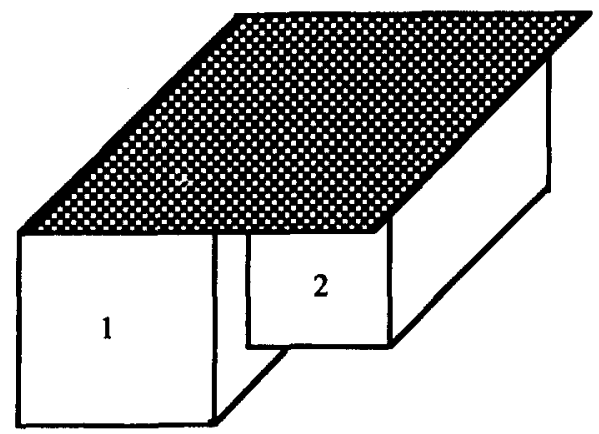

Fig. 1. Three dimensional two division rectangular pack with metal lid. 


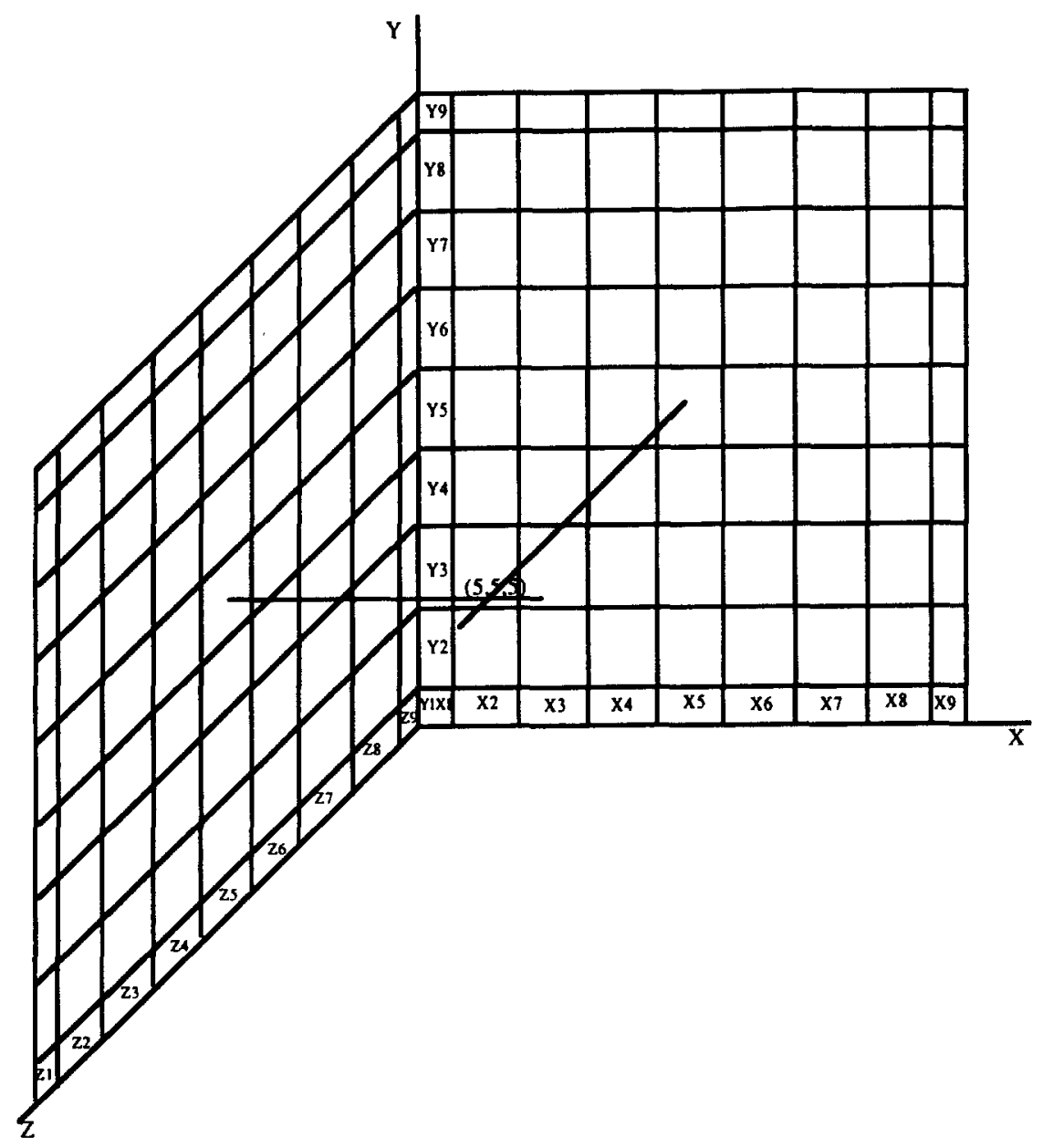

Fig. 2. Arrangement of nodes for one rectangular division of the package. The geometric centre has coordinates $(5,5,5)$.

allows the user to specify different surface heat transfer coefficients at the package lid and side and bottom walls.

Taking into account the cooling phase, the sterility value [10] was calculated in all the defined volume elements.

$$
F=\int_{0}^{t p} 10^{\left(T-T_{\mathrm{refm}}\right) / z_{\mathrm{m}}} \mathrm{d} t,
$$

where $F$ is the sterility value ( $\mathrm{min}), T$ the temperature at a given position and a function of time $\left({ }^{\circ} \mathrm{C}\right.$ ), $T_{\text {refm }}$ the reference temperature for the target microorganism $\left(121.1^{\circ} \mathrm{C}\right), z_{\mathrm{m}}$ the $z$-value for the target microoganism $\left(10^{\circ} \mathrm{C}\right)$, and $t p$ the total processing time $(\mathrm{min})$. The node having the smallest sterility value $\left(F_{\mathrm{L}}\right)$ was defined as the least lethality point [8]. 
The thermal impact on the level of microorganisms or quality attributes was calculated at a given position

$$
N / N_{0}=10^{-\frac{1}{D_{\text {ref }}} \int_{0}^{t \mathrm{p}} 10^{\left(T-T_{\mathrm{ref}}\right) / z} \mathrm{~d} t},
$$

or in terms of volume average [10]

$$
\left(N / N_{0}\right)_{\mathrm{ave}}=\frac{1}{V_{\mathrm{T}}} \int_{0}^{V_{\mathrm{T}}}\left(N / N_{0}\right) \mathrm{d} V,
$$

where $N$ is the level of microorganisms or quality attribute, $N_{0}$ the initial level of microorganisms or quality attribute, $T_{\mathrm{ref}}$ the reference temperature for the target microorganism or quality attribute, and $V_{\mathrm{T}}$ is the total volume $\left(\mathrm{m}^{3}\right)$.

\section{Results and discussion}

\subsection{Simulations to predict time-temperature profiles}

The computer program can be used to design adequate thermal processing conditions for the final safety of meals inside packages of the type shown in Fig. 1. The final quality in each division can also be evaluated.

Fig. 3 shows a typical time-temperature profile at the geometric centre of both divisions of the package.

It is obvious that if the division with the lower heating rate has the minimum required sterility value, the other division will be overprocessed. A few case studies were carried out to evaluate the extent of this overprocessing (Table 1). The final quality in each division can be very different. This was most notable with meal 2 , where a difference of $33 \%$ on the final volume average quality retention in each division was observed. Therefore, when the final quality of the overall meal has to be optimised, an adequate objective function, taking into consideration both divisions, must be used.

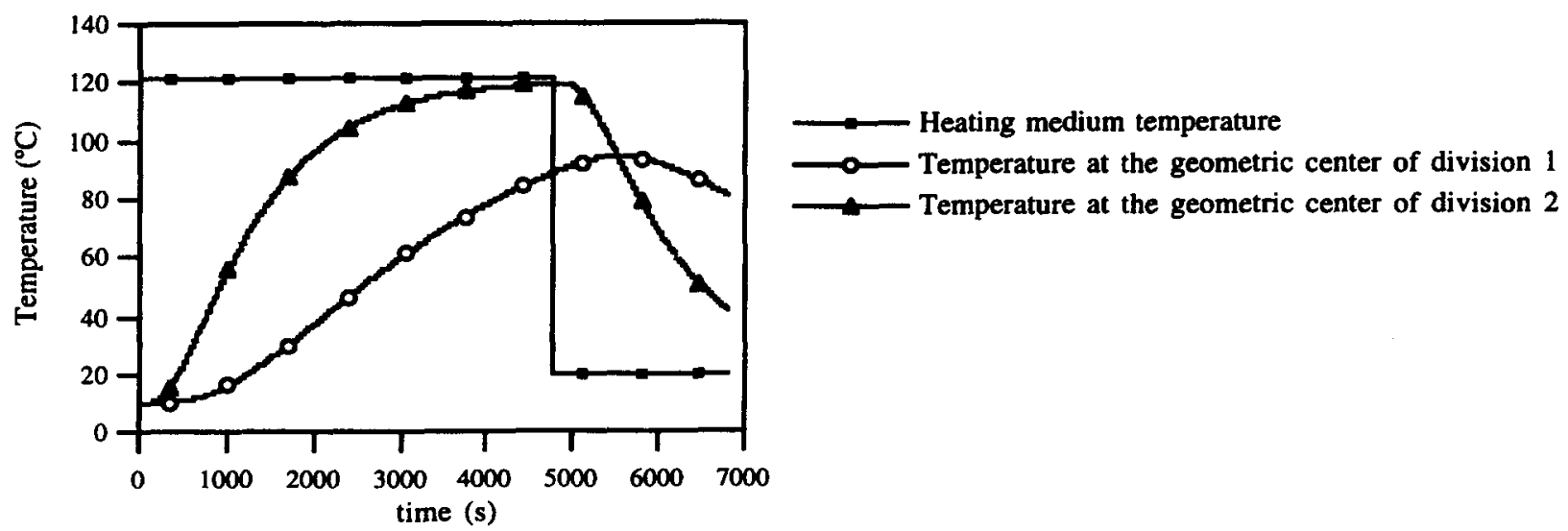

Fig. 3. Time-temperature profile in a two division rectangular package. The surface heat transfer coefficients were $600 \mathrm{~W} / \mathrm{m}^{2} / \mathrm{K}$ and $50 \mathrm{~W} / \mathrm{m}^{2} / \mathrm{k}$ at the package walls and lid, respectively. The thermal diffusivities and dimensions were $1.6 \times 10^{-7} \mathrm{~m}^{2} / \mathrm{s}$ and $(10 \times 8 \times 15) \mathrm{cm}^{3}$ and $1.7 \times 10^{-7} \mathrm{~m}^{2} / \mathrm{s}$ and $(5 \times 6 \times 10) \mathrm{cm}^{3}$ for divisions 1 and 2 , respectively. 
Table 1

Quality degradation of food products sterilised in a two division rectangular package with metal lid. The surface heat transfer coefficients were $600 \mathrm{~W} / \mathrm{m}^{2} / \mathrm{K}$ and $50 \mathrm{~W} / \mathrm{m}^{2} / \mathrm{K}$ at the package walls and lid, respectively. For the quality attribute the $z$-value was $25^{\circ} \mathrm{C}$ and the $D$-value $202 \mathrm{~min}$ [11]. Dimensions in the $x, y$ and $z$ direction were $0.05 \mathrm{~m}$

\begin{tabular}{lllllllll}
\hline Meal & Product & Division & $\begin{array}{l}\text { Thermal } \\
\text { diffusivity } \\
\times 10^{7}\left(\mathrm{~m}^{2} / \mathrm{s}\right)\end{array}$ & $\begin{array}{l}f_{\mathrm{h}} \\
(\mathrm{min})\end{array}$ & $\begin{array}{l}F_{\mathrm{c}} \\
(\mathrm{min})\end{array}$ & $\begin{array}{l}F_{\mathrm{L}} \\
(\mathrm{min})\end{array}$ & Node & $\begin{array}{l}\text { Volume } \\
\text { average } \\
\text { retention } \\
(\%)\end{array}$ \\
\hline 1 & Peas pureed & 1 & 1.82 & 22.48 & 2.99 & 2.66 & $(5,7,5)$ & 29.64 \\
& Meat croquette & 2 & 1.98 & 21.05 & 4.03 & 3.61 & $(5,7,5)$ & 27.21 \\
& Lima beans pureed & 1 & 1.80 & 22.73 & 8.40 & 7.82 & $(5,7,5)$ & 15.41 \\
& Beef tongue & 2 & 1.32 & 29.75 & 2.99 & 2.78 & $(5,7,5)$ & 23.22 \\
& Carrots & 1 & 1.40 & 28.20 & 3.01 & 2.76 & $(5,7,5)$ & 24.31 \\
& Chilli with meat & 2 & 1.66 & 24.37 & 5.58 & 5.14 & $(5,7,5)$ & 19.58 \\
\hline
\end{tabular}

\subsection{Study of the least lethality point position}

Considering only one rectangular part of the container, the least lethality point position was determined as a function of heat penetration rate $\left(f_{\mathrm{h}}\right)$ of the product (Table 2$)$ and surface heat transfer coefficient at the package lid (Table 4). Silva and Korczak [8] have identified that for cylindrical containers, these variables are the most important affecting this position.

It was concluded that, for uniform surface heat transfer coefficient, the least lethality point is always located at the axis of symmetry with the smallest dimension (Tables 2 and 3). For lower heat penetration rates (larger values of $f_{\mathrm{h}}$ ) this point moves towards the surface and the difference between the sterility value specified at the geometric centre and the same value at the least lethality point is more significant.

When a smaller surface heat transfer coefficient is specified only at the package lid, the least lethality point is always located in the vertical axis of symmetry and only for values smaller than approximately

Table 2

Location of the least lethality point as a function of heat penetration rate to the product. The surface heat transfer coefficient was $10 \mathrm{~W} / \mathrm{m}^{2} / \mathrm{K}$ and uniform. The $X$ dimension was $0.10 \mathrm{~m}$ and the thermal diffusivity $1.7 \times 10^{-7} \mathrm{~m}^{2} / \mathrm{s}$. The other $Y$ and $Z$ dimensions are shown in Table 3

\begin{tabular}{|c|c|c|c|c|c|c|c|c|c|}
\hline \multicolumn{10}{|c|}{$Y / Z$} \\
\hline & 0.1 & & & 0.5 & & & 1.0 & & \\
\hline$f_{\mathrm{h}}(\min )$ & $F_{\mathrm{c}}(\min )$ & $F_{\mathrm{L}}(\min )$ & Node & $F_{\mathrm{c}}(\min )$ & $F_{\mathrm{L}}(\min )$ & Node & $F_{\mathrm{c}}(\min )$ & $F_{\mathrm{L}}(\min )$ & Node \\
\hline 40 & 2.99 & 2.99 & $(5,5,5)$ & 2.99 & 2.98 & $(5,5,5)$ & 2.99 & 2.99 & $(5,5,5)$ \\
\hline 70 & 2.99 & 2.99 & $(5,5,5)$ & 2.99 & 2.97 & $\begin{array}{l}(5,8,5) \\
(5,2,5)\end{array}$ & 2.99 & 2.99 & $(5,5,5)$ \\
\hline 100 & 2.99 & 2.99 & $(5,5,5)$ & 2.99 & 2.96 & $\begin{array}{l}(5,7,5) \\
(5,3,5)\end{array}$ & 2.99 & 2.99 & $(5,5,5)$ \\
\hline 150 & 2.99 & 2.98 & $\begin{array}{l}(5,7,5) \\
(5,3,5)\end{array}$ & 2.99 & 2.93 & $\begin{array}{l}(5,7,5) \\
(5,3,5)\end{array}$ & 2.99 & 2.98 & $(5,5,5)$ \\
\hline 250 & 3.00 & 2.98 & $\begin{array}{l}(5,6,5) \\
(5,4,5)\end{array}$ & 2.99 & 2.87 & $\begin{array}{l}(5,7,5) \\
(5,3,5)\end{array}$ & 2.99 & 2.98 & $\begin{array}{l}(5,5,6)(5,5,4) \\
(5,6,5)(5,4,5)\end{array}$ \\
\hline 400 & 2.99 & 2.97 & $\begin{array}{l}(5,6,5) \\
(5.4 .5)\end{array}$ & 2.99 & 2.96 & $\begin{array}{l}(5,6,5) \\
(5.4 .5)\end{array}$ & 3.00 & 2.96 & $\begin{array}{l}(6,5,5) \\
(4.5 .5)\end{array}$ \\
\hline
\end{tabular}


Table 3

$Y$ and $Z$ dimensions used for case studies in Table 2

\begin{tabular}{rlrrrrr}
\hline & \multicolumn{5}{c}{$Y / Z$} \\
\hline$f_{\mathrm{h}}(\mathrm{min})$ & 0.1 & & 0.5 & $Z(\mathrm{~cm})$ & $Y(\mathrm{~cm})$ & $Z(\mathrm{~cm})$ \\
\hline 40 & $Y(\mathrm{~cm})$ & $Z(\mathrm{~cm})$ & $Y(\mathrm{~cm})$ & 1.4480 & 0.9652 & 0.9652 \\
70 & 0.5310 & 5.3100 & 0.7240 & 3.5684 & 1.7120 & 1.7120 \\
100 & 0.9440 & 9.4400 & 1.2842 & 3.7240 & 2.4820 & 2.4820 \\
150 & 1.3710 & 13.7100 & 1.8620 & 5.7360 & 3.8220 & 3.8220 \\
250 & 2.1200 & 21.2000 & 2.8680 & 10.1460 & 6.7522 & 6.7522 \\
400 & 3.7920 & 37.9200 & 5.0730 & 18.1280 & 12.0300 & 12.0300 \\
\hline
\end{tabular}

Table 4

Location of the least lethality point as a function of surface heat transfer coefficient $(h)$ at the package lid. The surface heat transfer coefficient at the package walls was $600 \mathrm{~W} / \mathrm{m}^{2} / \mathrm{K}$. Dimensions of the package were $0.05 \mathrm{~m}$ in all directions and the thermal diffusivity was $1.7 \times 10^{-7} \mathrm{~m}^{2} / \mathrm{s}$

\begin{tabular}{lllll}
\hline$f_{\mathrm{h}}(\min )$ & $h\left(\mathrm{~W} / \mathrm{m}^{2} / \mathrm{K}\right)$ & $F_{\mathrm{c}}(\min )$ & $F_{\mathrm{L}}(\min )$ & Node \\
\hline 26.5 & 10 & 3.01 & 2.12 & $(5,8,6)$ \\
23.9 & 50 & 3.01 & 2.69 & $(5,7,5)$ \\
22.8 & 100 & 2.99 & 2.91 & $(5,6,5)$ \\
22.2 & 150 & 3.02 & 2.99 & $(5,6,5)$ \\
22.0 & 200 & 3.02 & 3.01 & $(5,5,5)$ \\
21.6 & 300 & 3.00 & 3.00 & $(5,5,5)$ \\
\hline
\end{tabular}

$150 \mathrm{~W} / \mathrm{m}^{2} / \mathrm{K}$, the difference between the sterility values at the geometric centre and at the least lethality point is significant (Table 4). If different surface heat transfer coefficients at the pack lid and side and bottom walls are used, the location of the least lethality point is more difficult to predict.

\section{Conclusions}

A mathematical model was developed to describe the thermal sterilisation of conduction heating foods inside packages with two rectangular divisions. For these type of packs the most adequate sterility criteria is a target sterility value specified at the least lethality point of the division with lower heat transfer rate.

\section{References}

[1] G.S. Tucker, Modelling of heat transfer into plastic food containers, Packaging (1991) 19-25.

[2] J.E. Manson, J.W. Zahradnik and C.R. Stumbo, Evaluation of lethality and nutrient retentions of conduction-heating foods in rectangular containers, Food Tech. 24 (1970) 109-113.

[3] G.S. Tucker and P. Clark, Modelling the cooling phase of heat sterilization processes, using heat transfer coefficients, Internat. J. Food Sci. Tech. 25 (1990) 668-681.

[4] G. Tucker and D. Holdsworth, Optimisation of quality factors for foods thermally processed in rectangular containers, in: R.N. Field and J.A. Howell, eds., Process Engineering in the Food Industry 2: Convenience Foods and Quality Assurance (Elsevier, Amsterdam, 1990) 59-74.

[5] G.S. Tucker and S.D. Holdsworth, Mathematical modelling of sterilization and cooking processes for heat preserved foods - applications of a new heat transfer model, Trans. IChem.E 69, part C (1991) 5-12. 
[6] C.L.M. Silva, F.A.R. Oliveira and M. Hendrickx, Modelling optimum processing conditions for the sterilisation of prepackaged foods, Food control 4 (1993) 67-78.

[7] F. Flambert and J. Deltour, Localization of the critical area in thermally processed conduction heated canned food, Lebensm.-Wiss. U. Tech. 5 (1) (1972) 7-13.

[8] C. Silva and K. Korczak, Critical evaluation of restrictions used to optimise sterilisation processing conditions, 4th Bath Food process Engrg. Conf., 19-29 September 1994.

[9] C.L.M. Silva, Optimization of sterilized conduction heating foods: A generalized approach, Ph.D. Thesis, Escola Superior de Biotecnologia, Porto, 1993.

[10] C. Stumbo, Thermobacteriology in Food Processing, 2nd Edition (Academic Press, New York, 1973).

[11] E. Feliciotti and W.B. Esselen, Thermal destruction rates of thiamin in pureed meats and vegetables, Food Tech. 11, $77-84$. 